\title{
PRIMA-1 increases cisplatin sensitivity in chemoresistant ovarian cancer cells with p53 mutation: a requirement for Akt down-regulation
}

\author{
Noriko Kobayashi ${ }^{1,2}$, Mohammadreza Abedini ${ }^{1,3}$, Noriaki Sakuragi ${ }^{2}$ and Benjamin K Tsang ${ }^{1,4^{*}}$
}

\begin{abstract}
Background: Since ovarian cancer is associated with high frequency of p53 mutation, the availability of p53 reactivation and induction of massive apoptosis (PRIMA-1) offers a possible new therapeutic strategy for overcoming this devastating disease. Although Akt activation is believed to be a determinant in chemoresistance in ovarian cancer, whether Akt plays a role in regulating the effectiveness of PRIMA-1 in sensitizing chemoresistant ovarian cancer cells with p53 mutation to cisplatin (CDDP), remains to be determined.

Methods: In the present studies, we examined the influence of Akt down-regulation following dominant-negative (DN-Akt) expression on the ability of PRIMA-1 (0-10 $\mu \mathrm{M})$ to facilitate CDDP $(0-10 \mu \mathrm{M})$-induced apoptosis in p53-mutated chemoresistant ovarian cancer cells (A2780cp).

Results: Apoptosis rate was significantly higher at the combined treatment of low PRIMA-1 concentrations $(0.156-0.938 \mu \mathrm{M})$ plus CDDP $(10 \mu \mathrm{M})$ in the DN-Akt groups than control $(p<0.001)$. Apoptosis in cells treated with PRIMA-1 $(0.156 \mu \mathrm{M})$ and CDDP treatment $(10 \mu \mathrm{M})$ was significantly suppressed by p53-siRNA. PRIMA-1 increased phospho-p53 (Ser15) content in Akt down-regulated cells treated with CDDP.

Conclusions: These results demonstrate that PRIMA-1 can sensitize chemoresistant ovarian cancer cells with p53 mutation to CDDP when Akt is down-regulated, and the action of PRIMA-1 is associated with p53 activation. Our findings raise the possibility that PRIMA-1 may be useful candidate for adjuvant therapy with CDDP in chemoresistant ovarian cancer with p53 mutation when Akt is down-regulated.
\end{abstract}

Keywords: PRIMA-1, Chemoresistance, Ovarian cancer, Akt, p53, Cisplatin

\section{Introduction}

Ovarian cancer is the most lethal gynecological malignancies. Currently, the preferred treatment for ovarian cancer is combination chemotherapy, usually with a platinum based drug (e.g. CDDP or carboplatin), together with surgical debulking. The effectiveness of many of the chemotherapeutic agents in human cancer is highly dependent on the ability of the cancer cells to undergo drug-induced apoptosis. The development of

\footnotetext{
*Correspondence: btsang@ohri.ca

'Department of Obstetrics \& Gynecology and Cellular \& Molecular Medicine, University of Ottawa; Chronic Disease Program, Ottawa Hospital Research Institute, Ottawa K1H 8L6, Canada

${ }^{4}$ World Class University (WCU) Biomodulation Major, Department of Agricultural Biotechnology, College of Agriculture and Life Sciences, Seoul National University, Seoul, Republic of Korea

Full list of author information is available at the end of the article
}

chemoresistance is a major clinical problem for successful treatment in human ovarian cancer.

The tumor suppressor p53 inhibits tumor growth primarily by induction of apoptosis through mechanisms which are transcription-dependent $[1,2]$ and -independent [3-5]. p53 binds to a specific DNA sequence and transactivates target genes leading to cell cycle arrest and/or apoptosis. p53 dependent apoptosis is an important determining factor on the efficacy of chemotherapy, as tumors with p53 mutation are often more resistant to chemotherapeutic agents compared to those harboring wild-type p53 (wt-p53) [6,7]. Mutations in p53 occur in nearly half of human ovarian tumors. A majority being missense mutations in the DNA-binding core domain, thus resulting in deficient DNA binding [8].

\section{Biomed Central}

(c) 2013 Kobayashi et al.; licensee BioMed Central Ltd. This is an Open Access article distributed under the terms of the Creative Commons Attribution License (http://creativecommons.org/licenses/by/2.0), which permits unrestricted use, distribution, and reproduction in any medium, provided the original work is properly cited. 
Akt is a serine/threonine kinase activated by growth factors and cytokines in a phosphatidylinositol-3-OH-kinase (PI3K)-dependent manner [9,10]. Akt is implicated in cell proliferation and survival and is a key determinant of CDDP resistance in ovarian cancer cells which are p53 dependent [5]. We have previously demonstrated that Xiap, Akt and p53 interact in the regulation of chemosensitivity in ovarian cancer cells [2]. The PI3K-Akt pathway is over-expressed or activated in chemoresistant ovarian cancer cells and Akt down-regulation sensitizes chemoresistant wt-p53 cells to CDDP-induced apoptosis [2,11]. The latter response, however, is not evident in mutant-p53 cells unless reconstituted with wt-p53.

PRIMA-1, a low molecular weight compound, is more effective in inducing apoptosis in mutant-p53 cells than the wt-p53 cells and has noticeable anti-tumor activity in vitro and in vivo [12]. The sensitivity of PRIMA-1 was related to mutant p53 expression levels [13]. It is capable to induce apoptosis in human tumor cells through restoring the transcriptional function to mutant-p53 [14]. PRIMA-1 and the structural analog PRIMA-1 MET, also named APR-246, reactivate mutant p53 through covalent binding to the core domain and induce apoptosis in tumor cells. Its anti-tumor effect does not appear to be due to general toxicity [14]. Although PRIMA-1 is capable of restoring chemosensitivity in mutant-p53 cells, whether it acts synergistically with CDDP to inhibit proliferation of mutant-p53 ovarian cancer cells is unclear. Moreover, whether Akt plays a role in regulating the effectiveness of PRIMA-1 in sensitizing chemoresistant mutant-p53 ovarian cancer cells to CDDP, remains to be determined.

In the present studies, we have investigated the role of Akt in this regards and demonstrated that Akt downregulation induce significant apoptosis in combination treatment of PRIMA-1 and CDDP in chemoresistant ovarian cancer cells carrying p53 mutation.

\section{Materials and methods \\ Reagents}

Cells were cultured at $37^{\circ} \mathrm{C}$ with $5 \% \mathrm{CO} 2$ in DMEM (Dulbecco's modified Eagle's medium)/F12 (Invitrogen Inc., Burlington, ON, Canada). Medium was supplemented with $10 \%$ fetal bovine serum (FBS), streptomycin $(100 \mu \mathrm{g} / \mathrm{mL})$, penicillin $(100 \mathrm{U} / \mathrm{mL})$, and fungizone $(0.625 \mu \mathrm{g} / \mathrm{mL})$. PRIMA-1 was purchased from Calbiochem, Inc. (San Diego, CA, USA). Cis-diaminedichloroplatinum (CDDP) and Hoechst 33258 were supplied by Sigma (Oakville, ON, Canada). Adenoviral dominant-negative Akt (DN-Akt) was a gemerous gift from Dr. Kenneth Walsh (Cardiovascular Research, St. Elizabeth's Medical Centre, Boston, MA). Adenoviral LacZ was synthesized at the Neuroscience Research Institute, University of Ottawa (Ottawa, ON, Canada). Small inhibitory RNA (siRNA) to p53, scrambled sequence siRNA (control) and Mouse monoclonal anti-phospho-p53 (Ser15) were from Cell Signaling Technology Inc. (Beverly, MA, USA). Mouse monoclonal anti-glyceraldehyde phosphate dehydrogenase (GAPDH) was from Abcam (Cambridge, MA, USA).

\section{Cell culture, adenoviral infection and treatment of PRIMA-1 and CDDP}

Chemoresistant ovarian cancer cells (A2780cp: p53-mutant cell line) were cultured and treated as reported previously [2]. Cells were plated into $60 \mathrm{~mm}$ dishes in DMEM/F12 and infected with adenoviral DN-Akt construct $(\mathrm{MOI}=40)$ for $48 \mathrm{~h}$. Infection with adenoviral LacZ served as control and was used to normalize the total dose of adenovirus be same in each treatment group. Cells were treated with PRIMA-1 $(0-10 \mu \mathrm{M})$ for 8 hours, and then harvested at 24 hours following CDDP treatment $(0-10 \mu \mathrm{M})$. All CDDP treatment was performed in serum-free media.

\section{Assessment of apoptosis}

At the end of treatment period, cells attached to the growth surface were harvested by trypsin treatment. Floating and attached cells were then pooled and centrifuged, and the pellet were resuspended in phosphate buffered formalin (10\%) containing Hoechst $33258(12.5 \mathrm{ng} / \mathrm{ml})$. Cells were spotted onto slides and changes in nuclear morphology were observed using a Zeiss fluorescence microscope (magnification 400X), as previously reported [15,16]. A minimum of 200 cells with typical apoptotic nuclear morphology (nuclear shrinkage, condensation and fragmentation) were counted in each treatment group from randomly selected fields and expressed as the percentage of total cells $[3,17]$. The counter was "blinded" to sample identity to avoid experimental bias.

\section{Transfection with p53-siRNA}

After 12-18 hours of plating, cells were infected with adenoviral DN-Akt (MOI = 40; $48 \mathrm{~h}$ ). To determine if the action of PRIMA-1 was mediated by p53, the cells were, transfected with p53-specific or control siRNA (50 nM) $24 \mathrm{~h}$ after the infection and then treated with PRIMA-1 $(0.156 \mu \mathrm{M})$ for $8 \mathrm{~h}$. The cells were harvested at $24 \mathrm{~h}$ after CDDP treatment $(10 \mu \mathrm{M})$. p53 down-regulation was confirmed by Western blot analysis $[3,4,15,17]$.

\section{Protein extraction and Western blotting}

Protein extraction and Western blotting were performed as described previously [2]. Membranes were incubated overnight at $4^{\circ} \mathrm{C}$ with primary anti-p53 (1:1000), anti-GAPDH $(1: 2,000)$, and subsequently detected with horseradish peroxidase-conjugated goat IgG raised against the corresponding species. Peroxidase activity was visualized with an enhanced chemiluminescence (ECL) kit (Amersham Biosciences, Piscataway, NJ). Signal intensity 
was determined densitometrically using Scion Image software, version 4.02, from Scion Corporation (Frederick, MD, USA).

\section{Statistical analyses}

All results are expressed as mean \pm SEM of at least three independent experiments. Data were analyzed by two-way ANOVA and the differences between multiple experimental groups determined by Bonferoni post-hoc tests (PRISM software version 3.0, GrahPad, San Diego, CA). Statistical significance was inferred at $\mathrm{P}<0.05$.

\section{Results}

PRIMA-1 together with Akt down-regulation sensitizes chemoresistant ovarian cancer cells with mutant-p53 to CDDP in vitro

Tumor suppressive p53 is required for CDDP sensisitivity $[1,2]$. P53 mutation is often associated with chemoresistance in ovarian cancer [18]. We have previously demonstrated that CDDP is unable to induce apoptosis in p53-mutated ovarian cancer cells unless reconstituted with wt-p53 and Akt function down-regulated. To investigate whether PRIMA-1 increases CDDP sensitivity in mutant-p53 chemoresistant ovarian cancer cells and if its action is depending on Akt down-regulation, A2780cp cells were infected with adenoviral DN-Akt (MOI $=40$; LacZ as control) for $48 \mathrm{~h}$, treated with PRIMA-1 (0-10 $\mu \mathrm{M} ; 8 \mathrm{~h})$, and then harvested after CDDP treatment $(0-10 \mu \mathrm{M}$; $24 \mathrm{~h})$. As shown in Figure 1, in the presence of CDDP and DN-Akt, apoptosis rate was significantly higher in PRIMA-1 (0.156 - $10 \mu \mathrm{M} ; \mathrm{p}<0.01)$ than LacZ control. While PRIMA-1 alone was ineffective in the LacZ control groups, it significantly induced apoptosis in the DN-Akt groups in a concentration-dependent manner (0.938 $10 \mu \mathrm{M} ; \mathrm{p}<0.01)$. Apoptosis was significantly induced in the low concentration of PRIMA-1 (0.156 - $0.938 \mu \mathrm{M}$ : $\mathrm{p}<0.01)$ plus CDDP groups compared to PRIMA-1 alone group with DN-Akt $(\mathrm{p}<0.001)$, this response was not evident at higher concentrations $(1.25-10 \mu \mathrm{M} ; \mathrm{p}>0.05)$. There was no difference in apoptosis rate between PRIMA-1 alone groups and PRIMA-1 plus CDDP groups without DN-Akt.

To further examine the role of PRIMA-1 in the regulation of CDDP sensitivity, the above experiment carried out with different concentration of CDDP $(0-10 \mu \mathrm{M})$ and PRIMA-1 $(0.625 \mu \mathrm{M})$ which was strong enough to induce apoptosis in the combined treatment of CDDP in the absence and presence of DN-Akt. While CDDP was unable to induce apoptosis with LacZ control, PRIMA-1 and/or DN-Akt groups, it induces cell death in the presence of both PRIMA-1 and DN-Akt group in a concentration dependent manner (Figure 2). Apoptosis was significantly higher in the DN-Akt groups in a CDDP concentration $(5-10 \mu \mathrm{M})$ with maximal response observable at $0.625 \mu \mathrm{M}$ PRIMA-1 and $10 \mu \mathrm{M}$ CDDP.

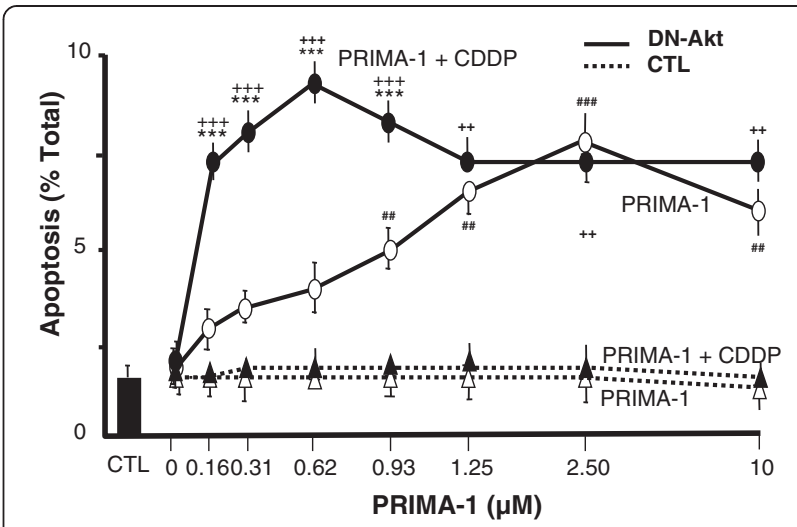

Figure 1 The effect of different concentration of PRIMA-1 on CDDP-induced apoptosis in chemoresistant p53-mutant ovarian cancer cells with/without Akt down-regulation. Apoptosis rate was evaluated with difference concentration of PRIMA-1 (0-10 $\mu \mathrm{M})$ plus CDDP $(0$ or $10 \mu \mathrm{M})$ using adenoviral DN-Akt $(-)$ or LacZ ( $\cdots \cdots$; as control). ${ }^{* * *} \mathrm{P}<0.001$; PRIMA-1+CDDP \& DN-Akt vs. PRIMA-1 \& DN-Akt; ${ }^{++} P<0.001,{ }^{++} P<0.01 ; P R I M A-1+C D D P \&$ DN-Akt vs. PRIMA-1+CDDP \& CTL; ${ }^{\# \# ~} \mathrm{P}<0.001,{ }^{\# \#} \mathrm{P}<0.01 ; \mathrm{PRIMA}-1+\mathrm{CDDP}$ \& DN-Akt vs. PRIMA-1 \& CTL. Results are expressed as mean \pm SEM of three independent experiments.

\section{p53 - specific action of PRIMA-1}

We next elucidated whether p53 is involved in the synergistic effect of PRIMA-1 and CDDP with DN-Akt (Figure 3). A2780cp cells were infected with adenovirus containing DN-Akt (MOI $=40 ; 48 \mathrm{~h})$, transfected with p53 or control siRNA, treated with least concentration of PRIMA-1 (0-0.156 $\mu \mathrm{M}$; able to induce significant apoptosis in above experiments; $8 \mathrm{~h}$ ), and harvested at $24 \mathrm{~h}$ following CDDP treatment (10 $\mu \mathrm{M} ; 24 \mathrm{~h})$. As demonstrated

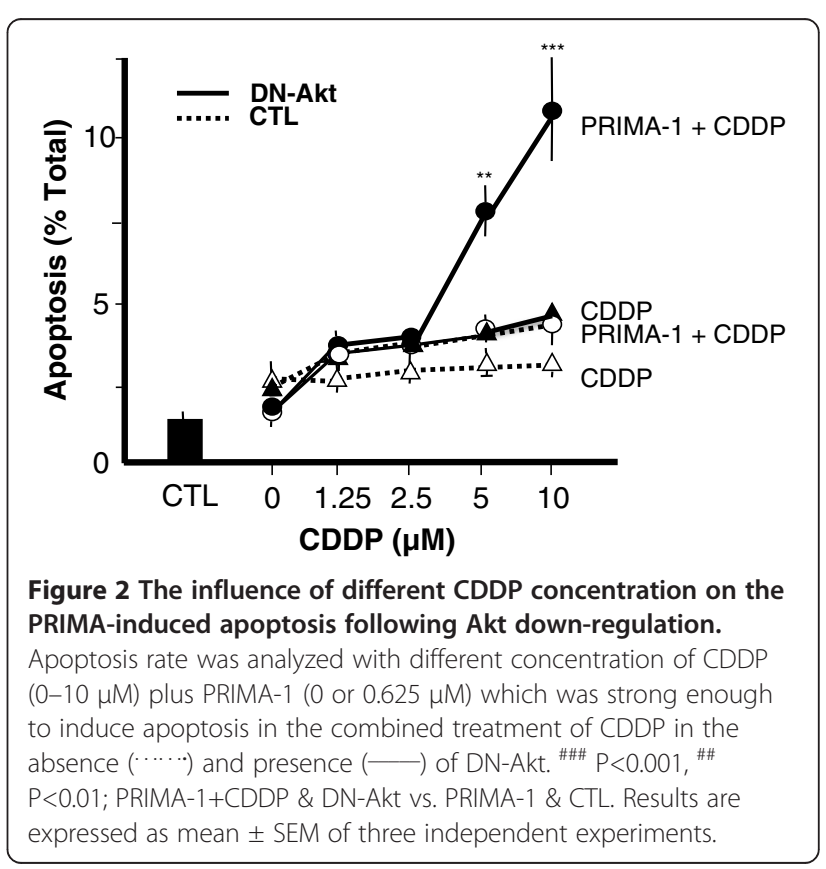




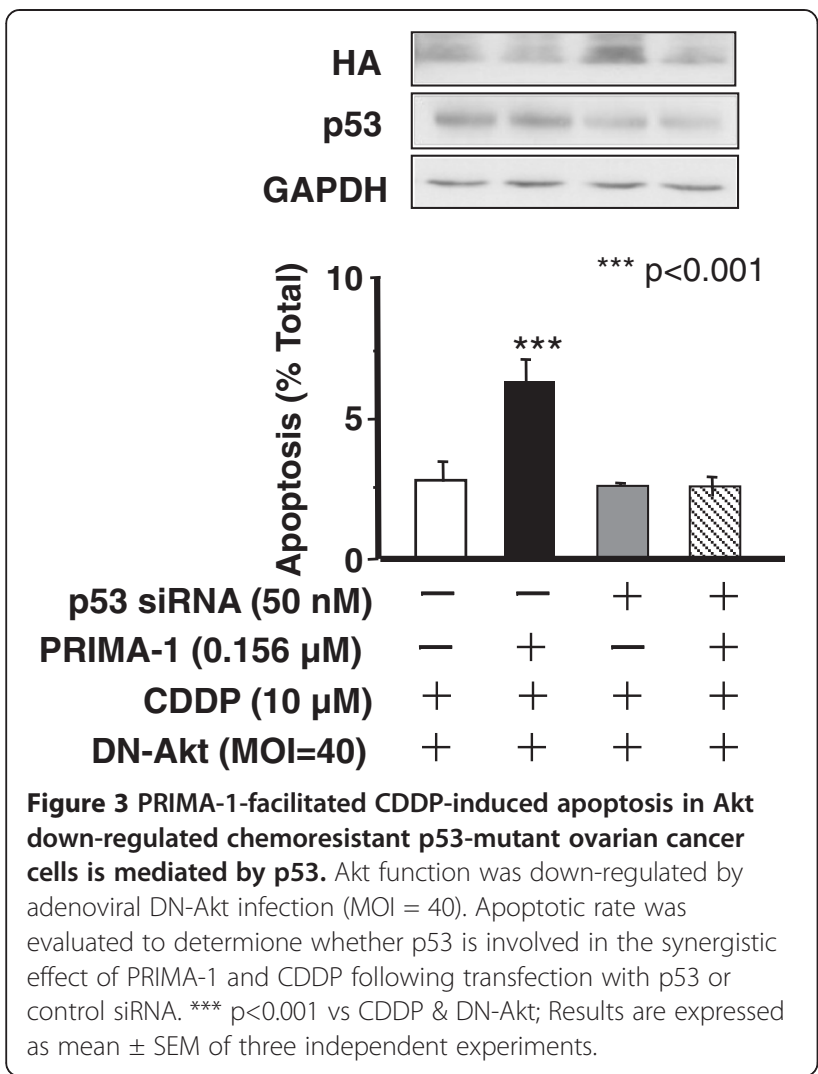

in Figure 3, PRIMA-1 and CDDP were unable to sensitize the cells neither in the presence of p53 nor control siRNA. However, the combination groups of PRIMA-1 and CDDP with DN-Akt dramatically induces apoptosis in the cells transfected with control siRNA, a response which was significantly suppressed in the group with p53-siRNA.

\section{The action of PRIMA-1 is associated with p53 activation} in vitro

PRIMA-1 sensitizes the effect of CDDP when Akt function is down-regulated in p53-mutant ovarian cancer cells. Although our data suggests that p53 is required for this effect, the mechanism involved is unclear. To determine whether the action of PRIMA-1 is mediated through p53 phosphorylation and thus its activation, phospho-p53 (Ser15) content in A2780cp cell extracts from the above experiments were determined by Western blot. As shown in Figure 4, p53 phosphorylation was not evident in LacZ group in the absence and presence of CDDP, although this response was detected with PRIMA-1 and DN-Akt alone and in the presence of CDDP. Down-regulation of Akt markedly enhanced this response, activated p53 and sensitized the cells in the induction of apoptosis by the combined treatment with PRIMA-1 and CDDP. PRIMA-1 increased phospho-p53 (Ser15) content in Akt downregulated cells treated with CDDP, suggesting that the action of PRIMA-1 in facilitating CDDP-induced apoptosis

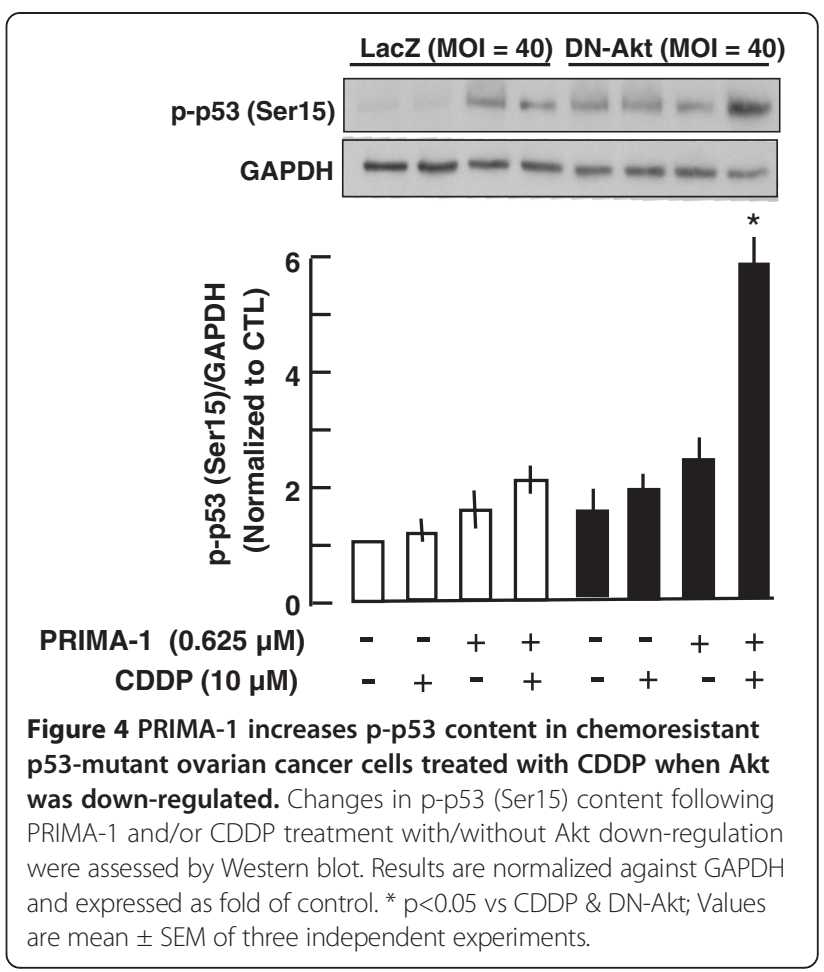

in p53 mutant chemoresistant ovarian cancer cells may in part be mediated through increased p53 phosphorylation at Ser15 (Figure 4).

\section{Discussion}

In the present study, we have shown that PRIMA-1 can sensitize chemoresistant ovarian cancer cells with p53 mutation to CDDP when Akt function is down-regulated. Our data also suggest that the action of PRIMA-1 is associated with p53 phosphorylation and activation. The mechanism by which PRIMA-1 sensitizes mutant p53 and induces apoptosis has not been well elucidated. Whether PRIMA-1 binds directly to mutant p53 or it acts through indirect mechanisms remains an opened question. p53 binds to a specific DNA sequence and transactivates target genes involved in the regulation of cell cycle arrest and apoptosis. Tumor cells containing wt-p53 are usually more chemosensitive than those bearing mutant $\mathrm{p} 53$. We have previously shown that while CDDP up-regulates p53 in CDDP-sensitive wt-p53 cells (OV2008), but not its resistant wt-p53 variant $\left(\mathrm{C} 13^{*}\right)$ in vitro, suggesting that regulation of p53 content/function by CDDP may be an important determinant of sensitivity [2].

PRIMA-1 synergizes with chemotherapeutic drugs to induce tumor cell apoptosis [12,19-21]. PRIMA-1 restores wild-type confirmation to mutant p53 by binding to the core and induces apoptosis in human tumor cells. Whereas wt-p53 is rapidly degraded by MDM2 in normal cells, the mutant p53 protein fails to undergo degradation in tumor cells and accumulates extensively [22]. Several 
studies have demonstrated that PRIMA-1 is able to restore the sequence-specific DNA-binding and to transactivate some mutant $\mathrm{p} 53$ proteins in vitro and to induce apoptosis in vivo [12,23-25]. p53 activates many genes involved in cell cycle arrest and apoptosis, mainly through its transcription-dependent activity [26,27]. It is essential that p53 reactivation in tumor cells trigger apoptosis rather than cell arrest, as the therapeutic goal is to kill the tumor cells. Heat shock protein 90 is a candidate target for p53 mutation reactivation by PRIMA-1 in breast cancer cells [28]. Some data have indicated that treatment with PRIMA-1 leads to upregulation of at least some of p53 target genes; for example, Bax and Noxa but not c-JunNH2-kinase (JNK) signaling [29,30]. On the other hand, $\mathrm{Li}$ et al. reported that JNK pathway plays an important role on PRIMA-1-induced apoptosis [31]. Others have shown that PRIMA-1 is capable of inducing apoptosis in a transcription independent manner [32] or even mutant p53-independent [33]. It has also been reported that PRIMA- 1 induces activation of caspase-2, caspase- 3 and caspase-9, consistent with induction of apoptosis via the mitochondrial pathway [25]. Microarray analysis revealed that PRIMA-1 induces a limited set of genes in a mutant p53-dependent manner, followed by ER stress [34].

Akt activation promotes cell survival, suppresses apoptotic death and confers resistance of ovarian cancer cells to CDDP-induced apoptosis [2,11,35]. Over-expression/activation of the PI3K-Akt pathway is commonly observed in ovarian cancer [36,37]. However, precisely how Akt controls p53 activation is still unclear. Activation of Akt promotes the entry of MDM2 into the nucleus and its interaction with the tumor suppressor protein p53. Binding of MDM2 to p53 inhibits the transcriptional activity of p53 and targets it for proteasomal degradation [38]. We previously demonstrated that activated Akt is an important regulator of both X-linked inhibitor of apoptosis protein (Xiap) and p53 levels after CDDP challenge and that p53 mutational status is a determinant of Akt-mediated chemoresistance $[2,11]$. Inhibition of Akt activity facilitated the CDDP-induced mitochondrial release and nuclear accumulation of apoptosis-inducing factor (AIF)-dependent, CDDP-induced apoptosis [39]. Activation of Akt confers resistance by blocking p53-mediated transactivation and p53 phosphorylation [1]. In the present study, suppression of Akt sensitized chemoresistant cells to CDDP in a p53dependent manner, suggesting a functional link between Akt-mediated chemoresistance and p53.

Recent data demonstrated that p53 is essential for CDDP-induced apoptosis in human ovarian cancer cells, and that p53-mediated apoptosis is dependent on the phosphorylation of several N-terminal residues, including Ser15, Ser20 and Ser37 [40-42]. Our previous data suggested that this is mediated, at least in part, through the phosphorylation of p53 on Ser15 and Ser20 [1]. As Ser15 phosphorylation affects p53 stability [43], phosphorylation of p53 at serine 15 by PRIMA- 1 seems to be involved in the reactivation of p53 transcriptional function. Mutation of Ser15 to Ala significantly attenuates p53-mediated apoptosis [42]. Our data show that down-regulation of Akt sensitizes the cells to CDDP-induced apoptosis and p-p53 at Ser15 is associated in the PRIMA-1-CDDP interaction, suggesting that Ser15 phosphorylation is needed for its function and apoptosis. This also suggests that CDDP induces p53 phosphorylation on Ser15 residue, which absent in chemoresistant cells and is required for CDDP-induced apoptosis. Akt efficiently blocks this processes, thereby conferring resistance to CDDP-induced apoptosis. In addition, while Akt modulates other p53-dependent cellular events, including the downregulation of FLIP, our evidence suggests that effective p53 phosphorylation and activation is essential for CDDPinduced apoptosis. Thus, it will be of interest to study the effects of chemotherapy on total and phospho-p53 in human ovarian tumors. Moreover, since Akt attenuates both processes, it is important to study the relationship between activation/overexpression of Akt in ovarian tumors and sensitivity to CDDP.

In summary, inhibition of Akt activity may represent a novel therapeutic approach to the combined treatment of PRIMA-1 and CDDP. Further examination of the role and regulation of Akt in the PRIMA-1-CDDP interaction in the ovarian tumour xenograft might provide novel insights into a possible new therapy for chemoresistant ovarian cancer.

\section{Competing interests}

The authors declare no conflict of interests.

\section{Authors' contributions}

NK carried out the the experiments and drafted the manuscript. MRA participated in the design of the studies, reviewed the data and revised the manuscript. NS and BKT provided input in the project, reviewed the data and the manuscript. All authors read and approved the final manuscript.

\section{Acknowledgment}

This work was supported by grants from the Canadian Institutes of Health Research (MOP-10369), and the World Class University (WCU) program through the National Research Foundation of Korea and funded by the Ministry of Education, Science and Technology (R31-10056). NK is a recipient of a CIHR-STIRRH Postdoctoral Fellowship.

\section{Author details}

'Department of Obstetrics \& Gynecology and Cellular \& Molecular Medicine, University of Ottawa; Chronic Disease Program, Ottawa Hospital Research Institute, Ottawa K1H 8L6, Canada. ${ }^{2}$ Department of Gynecology, Hokkaido University Graduate School of Medicine and School of Medicine, Sapporo, Japan. ${ }^{3}$ Cellular and Molecular Medicine Research Center, Department of Physiology and Pharmacology, Birjand University of Medical Sciences, Birjand, Iran. "World Class University (WCU) Biomodulation Major, Department of Agricultural Biotechnology, College of Agriculture and Life Sciences, Seoul National University, Seoul, Republic of Korea.

Received: 7 October 2012 Accepted: 18 January 2013

Published: 26 January 2013 


\section{References}

1. Fraser M, Bai T, Tsang BK: Akt promotes cisplatin resistance in human ovarian cancer cells through inhibition of p53 phosphorylation and nuclear function. Int J Cancer 2008, 122:534-546.

2. Fraser M, Leung BM, Yan X, Dan HC, Cheng JQ, Tsang BK: $\mathrm{p} 53$ is a determinant of X-linked inhibitor of apoptosis protein/Akt-mediated chemoresistance in human ovarian cancer cells. Cancer Res 2003, 63:7081-7088

3. Abedini MR, Muller EJ, Bergeron R, Gray DA, Tsang BK: Akt promotes chemoresistance in human ovarian cancer cells by modulating cisplatininduced, p53-dependent ubiquitination of FLICE-like inhibitory protein. Oncogene 2010, 29:11-25.

4. Abedini MR, Muller EJ, Brun J, Bergeron R, Gray DA, Tsang BK: Cisplatin induces p53-dependent FLICE-like inhibitory protein ubiquitination in ovarian cancer cells. Cancer Res 2008, 68:4511-4517.

5. Yang X, Fraser M, Moll UM, Basak A, Tsang BK: Akt-mediated cisplatin resistance in ovarian cancer: modulation of p53 action on caspasedependent mitochondrial death pathway. Cancer Res 2006, 66:3126-3136.

6. Fujiwara T, Grimm EA, Mukhopadhyay T, Zhang WW, Owen-Schaub LB, Roth $J A$ : Induction of chemosensitivity in human lung cancer cells in vivo by adenovirus-mediated transfer of the wild-type p53 gene. Cancer Res 1994, 54:2287-2291.

7. Rusch V, Klimstra D, Venkatraman E, Oliver J, Martini N, Gralla R, et al: Aberrant p53 expression predicts clinical resistance to cisplatin-based chemotherapy in locally advanced non-small cell lung cancer. Cancer Res 1995, 55:5038-5042

8. Olivier M, Eeles R, Hollstein M, Khan MA, Harris CC, Hainaut P: The IARC TP53 database: new online mutation analysis and recommendations to users. Hum Mutat 2002, 19:607-614.

9. Franke TF, Hornik CP, Segev L, Shostak GA, Sugimoto C: PI3K/Akt and apoptosis: size matters. Oncogene 2003, 22:8983-8998.

10. Fresno Vara JA, Casado E, de Castro J, Cejas P, Belda-Iniesta C, Gonzalez-Baron M: PI3K/Akt signalling pathway and cancer. Cancer Treat Rev 2004, 30:193-204.

11. Dan HC, Sun M, Kaneko S, Feldman Rl, Nicosia SV, Wang HG, et al: Akt phosphorylation and stabilization of X-linked inhibitor of apoptosis protein (XIAP). J Biol Chem 2004, 279:5405-5412.

12. Bykov VJ, Zache N, Stridh H, Westman J, Bergman J, Selivanova G, et al: PRIMA-1 (MET) synergizes with cisplatin to induce tumor cell apoptosis. Oncogene 2005, 24:3484-3491.

13. Bykov VJ, Issaeva N, Selivanova G, Wiman KG: Mutant p53-dependent growth suppression distinguishes PRIMA-1 from known anticancer drugs: a statistical analysis of information in the National Cancer Institute database. Carcinogenesis 2002, 23:2011-2018.

14. Bykov VJ, Issaeva N, Shilov A, Hultcrantz M, Pugacheva E, Chumakov P, et al: Restoration of the tumor suppressor function to mutant $\mathrm{p} 53$ by a low-molecular-weight compound. Nat Med 2002, 8:282-288.

15. Abedini MR, Qiu Q, Yan X, Tsang BK: Possible role of FLICE-like inhibitory protein (FLIP) in chemoresistant ovarian cancer cells in vitro. Oncogene 2004, 23:6997-7004.

16. Sasaki H, Sheng Y, Kotsuji F, Tsang BK: Down-regulation of X-linked inhibitor of apoptosis protein induces apoptosis in chemoresistant human ovarian cancer cells. Cancer Res 2000, 60:5659-5666.

17. Ali AY, Abedini MR, Tsang BK: The oncogenic phosphatase PPM1D confers cisplatin resistance in ovarian carcinoma cells by attenuating checkpoint kinase 1 and p53 activation. Oncogene 2012, 31:2175-86.

18. Kmet LM, Cook LS, Magliocco AM: A review of p53 expression and mutation in human benign, low malignant potential, and invasive epithelial ovarian tumors. Cancer 2003, 97:389-404.

19. Magrini R, Russo D, Ottaggio L, Fronza G, Inga A, Menichini P: PRIMA-1 synergizes with adriamycin to induce cell death in non-small cell lung cancer cells. J Cell Biochem 2008, 104:2363-2373.

20. Nahi H, Lehmann S, Mollgard L, Bengtzen S, Selivanova G, Wiman KG, et al: Effects of PRIMA-1 on chronic lymphocytic leukaemia cells with and without hemizygous p53 deletion. Br J Haematol 2004, 127:285-291.

21. Nahi H, Merup M, Lehmann S, Bengtzen S, Mollgard L, Selivanova G, et al: PRIMA-1 induces apoptosis in acute myeloid leukaemia cells with p53 gene deletion. Br J Haematol 2006, 132:230-236.

22. Lane DP: Cancer. p53, guardian of the genome. Nature 1992, 358:15-16.

23. Liang Y, Besch-Williford C, Benakanakere I, Hyder SM: Re-activation of the p53 pathway inhibits in vivo and in vitro growth of hormone-dependent human breast cancer cells. Int J Oncol 2007, 31:777-784.
24. Liang Y, Besch-Williford C, Hyder SM: PRIMA-1 inhibits growth of breast cancer cells by re-activating mutant p53 protein. Int J Oncol 2009, 35:1015-1023

25. Shen J, Vakifahmetoglu H, Stridh H, Zhivotovsky B, Wiman KG: PRIMA-1MET induces mitochondrial apoptosis through activation of caspase-2. Oncogene 2008, 27:6571-6580.

26. Horn HF, Vousden KH: Coping with stress: multiple ways to activate p53. Oncogene 2007, 26:1306-1316.

27. Vogelstein B, Lane D, Levine AJ: Surfing the p53 network. Nature 2000, 408:307-310.

28. Rehman A, Chahal MS, Tang X, Bruce JE, Pommier Y, Daoud SS: Proteomic identification of heat shock protein 90 as a candidate target for p53 mutation reactivation by PRIMA-1 in breast cancer cells. Breast Cancer Res 2005, 7:765-774.

29. Wang T, Lee K, Rehman A, Daoud SS: PRIMA-1 induces apoptosis by inhibiting JNK signaling but promoting the activation of Bax. Biochem Biophys Res Commun 2007, 352:203-212.

30. Wiman KG: Pharmacological reactivation of mutant $\mathrm{p} 53$ : from protein structure to the cancer patient. Oncogene 2010, 29:4245-4252.

31. Li Y, Mao Y, Brandt-Rauf PW, Williams AC, Fine RL: Selective induction of apoptosis in mutant $\mathrm{p} 53$ premalignant and malignant cancer cells by PRIMA-1 through the c-Jun-NH2-kinase pathway. Mol Cancer Ther 2005, 4:901-909.

32. Chipuk JE, Maurer U, Green DR, Schuler M: Pharmacologic activation of p53 elicits Bax-dependent apoptosis in the absence of transcription. Cancer Cell 2003, 4:371-381.

33. Supiot S, Zhao H, Wiman K, Hill RP, Bristow RG: PRIMA-1(met) radiosensitizes prostate cancer cells independent of their MTp53-status. Radiother Oncol 2008, 86:407-411.

34. Lambert JM, Moshfegh A, Hainaut P, Wiman KG, Bykov VJ: Mutant p53 reactivation by PRIMA-1MET induces multiple signaling pathways converging on apoptosis. Oncogene 2010, 29:1329-1338.

35. Asselin E, Mills GB, Tsang BK: XIAP regulates Akt activity and caspase-3dependent cleavage during cisplatin-induced apoptosis in human ovarian epithelial cancer cells. Cancer Res 2001, 61:1862-1868.

36. Sun $\mathrm{M}$, Wang G, Paciga JE, Feldman RI, Yuan ZQ, Ma XL, et al: AKT1/ PKBalpha kinase is frequently elevated in human cancers and its constitutive activation is required for oncogenic transformation in NIH3T3 cells. Am J Pathol 2001, 159:431-437.

37. Yuan ZQ, Feldman RI, Sussman GE, Coppola D, Nicosia SV, Cheng JQ: AKT2 inhibition of cisplatin-induced JNK/p38 and Bax activation by phosphorylation of ASK1: implication of AKT2 in chemoresistance. J Biol Chem 2003, 278:23432-23440.

38. Mayo LD, Donner DB: A phosphatidylinositol 3-kinase/Akt pathway promotes translocation of MDM2 from the cytoplasm to the nucleus. Proc Natl Acad Sci USA 2001, 98:11598-11603.

39. Yang X, Fraser M, Abedini MR, Bai T, Tsang BK: Regulation of apoptosis-inducing factor-mediated, cisplatin-induced apoptosis by Akt. Br J Cancer 2008, 98:803-808.

40. Bulavin DV, Saito S, Hollander MC, Sakaguchi K, Anderson CW, Appella E, et al: Phosphorylation of human $\mathrm{p} 53$ by $\mathrm{p} 38$ kinase coordinates $\mathrm{N}$-terminal phosphorylation and apoptosis in response to UV radiation. EMBO J 1999, $18: 6845-6854$

41. Shono T, Tofilon PJ, Schaefer TS, Parikh D, Liu TJ, Lang FF: Apoptosis induced by adenovirus-mediated p53 gene transfer in human glioma correlates with site-specific phosphorylation. Cancer Res 2002, 62:1069-1076.

42. Unger T, Sionov RV, Moallem E, Yee CL, Howley PM, Oren M, et al: Mutations in serines 15 and 20 of human p53 impair its apoptotic activity. Oncogene 1999, 18:3205-3212.

43. Shieh SY, Ikeda M, Taya Y, Prives C: DNA damage-induced phosphorylation of p53 alleviates inhibition by MDM2. Cell 1997, 91:325-334.

\section{doi:10.1186/1757-2215-6-7}

Cite this article as: Kobayashi et al:: PRIMA-1 increases cisplatin sensitivity in chemoresistant ovarian cancer cells with $\mathrm{p} 53$ mutation: a requirement for Akt down-regulation. Journal of Ovarian Research 2013 $6: 7$. 